\title{
Estudo clínico em lúpus: falha na medicação ou falha no desenho do estudo
}

(C) 2011 Elsevier Editora Ltda. Todos os direitos reservados.

A heterogeneidade das manifestações do lúpus representa importante desafio para o desenho de estudos clínicos. O pleomorfismo das manifestações clínicas, a gravidade da doença, a influência da etnia na sua atividade e os obstáculos para a realização de estudos com amostras maiores dificultam a obtenção de significância estatística nos ensaios clínicos para novas terapias. Muitos desses estudos excluem pacientes com manifestações renais e do sistema nervoso central, na tentativa de detectar eficácia em estágios menos graves da doença. Neste editorial tecemos alguns comentários gerais sobre estudos recentes.

O estudo EXPLORER arrolou 257 pacientes com lúpus extrarrenal e atividade variando de moderada a grave. Os pacientes foram randomizados para receber rituximabe e prednisona ou placebo e prednisona, tendo sido acompanhados por 78 semanas. Os desfechos primários e secundários do estudo não foram atingidos. O estudo LUNAR arrolou pacientes com nefrite lúpica comprovada por biópsia. O desenho geral foi semelhante ao do EXPLORER, e o sucesso foi definido como resposta renal em um ano. O uso do medicamento não teve impacto nos desfechos primários e secundários.

$\mathrm{O}$ estudo The efficacy and safety of abatacept in patients with non-life-threatening manifestations of systemic lupus erythematosus: results of a twelve-month, multicenter, exploratory, phase IIb, randomized, double-blind, placebo-controlled trial (Eficácia e segurança do abatacepte em pacientes com lúpus eritematoso sistêmico e manifestações que não oferecem risco de morte: resultados de um estudo randomizado, multicêntrico, exploratório, fase IIb, duplo-cego, controlado com placebo, de 12 meses) avaliou o efeito de abatacepte na exacerbação da doença em um contexto de uso de glicocorticoides orais. Para serem incluídos na pesquisa os pacientes deveriam apresentar exacerbação de lúpus nos 14 dias anteriores à sua entrada no estudo e utilizar dose estável de prednisona inferior a $30 \mathrm{mg} / \mathrm{dia}$. Foram tratados 175 pacientes: 118 randomizados para receber abatacepte e 57 para receber placebo. O estudo não mostrou diferença nas taxas de exacerbação para as categorias BILAG A e B. ${ }^{1}$

Belimumabe é um anticorpo monoclonal humano que inibe o fator estimulante de linfócitos B (B-lymphocyte stimulator - BLyS), e mostrou-se mais eficiente que placebo no tratamento de indivíduos com lúpus eritematoso sistêmico (LES) sorologicamente ativo. Análises de eficácia incluíram os índices de atividade da doença SELENA-SLEDAI, BILAG e SELENA-SLEDAI Flare Index (SFI). O desfecho primário ocorreu na semana 52, com melhora em várias aferições empregadas, inclusive a avaliação global pelo médico. O sucesso de belimumabe em 52 semanas (BLISS-52) pode ter resultado de uma nova subanálise em subpopulação de pacientes que melhorou com o tratamento. A maioria dos pacientes mostrou estar na categoria "B" quanto à atividade da doença, o que significa que tinham mais autoanticorpos, inclusive títulos mais elevados de anti-DNA e níveis mais altos de imunoglobulinas séricas.

\section{Considerações gerais importantes}

Estudos futuros poderiam analisar se existe um racional científico para que a avaliação de eficácia de tratamento enfoque a redução do número de exacerbações versus a diminuição persistente da atividade da doença. Pacientes com LES e exacerbações periódicas podem diferir daqueles com lúpus cronicamente ativo. Pacientes com LES de grupos raciais diferentes podem apresentar patologias e condições diferentes, com um único paciente apresentando diferentes variações ao longo do tempo. Os estudos futuros devem dar especial atenção à etnia como um fator que pode afetar o desfecho. O tamanho do estudo também é um importante desafio. Em geral, quanto maior o estudo, maior a probabilidade de se perder um efeito terapêutico nas análises. Por fim, um pequeno estudo pode obter êxito e resultados estatisticamente significativos. Outros pontos a se considerar são tempo de doença, atual envolvimento de órgãos específicos e tratamentos anteriores. Por fim, a 
definição de melhora dos desfechos usada em estudos deveria ser aceita universalmente como a melhor disponível. Controvérsias em torno do uso do índice BILAG baseiam-se em uma abordagem de intenção de tratar de acordo com uma extensa série de critérios para classificar pacientes com manifestações de LES surgindo em diferentes sistemas de órgãos. Há limitações com o uso do índice BILAG isolado; por exemplo, o uso de BILAG B como medida de desfecho de atividade lúpica deveria ser considerado simultaneamente ao uso de outros índices. ${ }^{2}$

\section{CONCLUSÕES}

Considerando-se o sucesso dos estudos sobre artrite reumatoide (AR), seria de se esperar que o mesmo acontecesse com o LES, mas isso não se mostrou verdadeiro. Espera-se que possamos aprender com os nossos erros atuais e criar novos e diferentes elementos de desenho clínico, assim como que as considerações aqui esboçadas para estudos futuros possam auxiliar na discriminação entre falha medicamentosa e falha no desenho do estudo.

\section{Morton Aaron Scheinberg, PhD}

Clínico e Reumatologista do Hospital Israelita Albert Einstein Diretor científico e Coordenador de Pesquisa Clínica do Hospital Abreu Sodré - AACD

Professor Llivre-Docente em Imunologia pela Universidade de São Paulo - USP $\mathrm{PhD}$ em Imunologia pela Universidade de Boston

\section{REFERENCES}

\section{REFERÊNCIAS}

1. Merrill JT, Burgos-Vargas R, Westhovens R, Chalmers A, D'Cruz D, Wallace DJ et al. The efficacy and safety of abatacept in patients with non-life-threatening manifestations of systemic lupus erythematosus: results of a twelve-month, multicenter, exploratory, phase IIb, randomized, double-blind, placebo-controlled trial. Arthritis Rheum 2010; 62(10):3077-87.

2. Peirce A, Lipsky P, Schwartz BD. Mitigate Risk and Increase Success of Lupus Clinical Trials - Design strategies from a Lupus Research Institute conference. The Rheumatologist, August 2010. Available from: www.the-rheumatologist.org/details/article/863303/Mitigate Risk_and_Increase_Success_of_Lupus_Clinical_Trials.html. 